\title{
Studien über den Vorrat an einigen Aminosäuren bei verschiedenen Tierarten.
}

Von

Emil Abderhalden, Alfred Gigon und Eduard Strauss.

(Aus dem I. Chemischen Institut der Universität Berlin.)

(Der Redaktion zugegangen am 17. März 1907.)

Unsere Kenntnisse über den Verlauf des intermediären Eiweißstoffwechsels sind noch sehr lückenhaft. Wir stellen uns vor, daß beim Abbau der Proteine durch die Körperzellen zunächst Aminosäuren sich bilden, und erst diese weiter abgebaut werden. Mancherlei Beobachtungen sprechen für diese Ansicht. Es ist allerdings bis jetzt unter normalen Verhältnissen nicht gelungen, in den Geweben und im Blute Eiweißabbauprodukte in einwandfreier Weise direkt an Ort und Stelle nachzuweisen, dagegen findet man solche unter mannigfachen pathologischen Bedingungen. Es ist dagegen geglückt, durch Einführung bestimmter Verbindungen intermediäre Eiweißabbauprodukte gewissermaßen abzufangen und vor dem weiteren Abbau zu schützen, so das Glykokoll und das Ornithin nach Eingabe von Benzoesäure an den Säugetier- resp. Vogelorganismus und das Cystin nach Zufuhr von Halogenbenzol. Ferner wissen wir, speziell nach den Untersuchungen im hiesigen Institute, daß offenbar in allen Organen Fermente vorhanden sind, welche Aminosäureketten (Polypeptide) spalten, und als Produkte der Hydrolyse erhält man Aminosäuren. Auch die Tatsache ist von Bedeutung, daß der Stickstoff von verfütterten oder subkutan eingeführten Aminosäuren als Harnstoff im Urin erscheint, wenigstens gilt dies für den Organismus des Hundes. Wir müssen zugeben, daß uns alle diese Beobachtungen nicht berechtigen, mit voller Bestimmtheit zu behaupten, daß der Eiweißabbau im intermediären Stoffwéchsel wirklich stets so verläuft, wie wir ihn geschildert haben. Es 
ist möglich, daß z. B. die Desamidierung viel früher einsetzt, d. h. an komplizierteren Produkten, und es somit gar nicht zur Bildung von Aminosäuren kommt. Es ist gar nicht unwahrscheinlich, daß der Eiweißabbau in den Geweben nicht nach einem Schema verläuft, sondern sich den Verhältnissen anpaßt. Ein genaueres Studium der Zuckerbildung aus Eiweiß, speziell beim Diabetes, dürfte berufen sein, nach dieser Richtung manche neue Gesichtspunkte zu liefern.

Sehr unbestimmt ist es auch, welche Proteine im normalen Eiweißstoffwechsel zum Abbau gelangen. Wir wissen nur soviel, daß eine dem zugeführten Stickstoff bei Stickstoffgleichgewicht entsprechende Menge Stickstoff im Urin wiedererscheint. So nahe es liegt, nun anzunehmen, daß das zugeführte Eiweiß sofort in den Geweben verbrannt wird, so störend wirkt gerade für diese Vorstellung der Umstand, daß jedes Individuum eine auffallend große Menge Eiweiß unbedingt nötig hat, soll nicht der eigene Körperbestand angegriffen werden. So einfach können die Verhältnisse nicht liegen! Würde das zugeführte Eiweiß sofort glatt verbrannt, so wäre es nach unseren sonstigen Vorstellungen schwer verständlich, weshalb eine bestimmte Eiweißmenge nötig ist, und weshalb der tierische Organismns nicht mit Produkten auskommt, die der Eiweißgruppe zwar angehören, jedoch nicht alle Bausteine enthalten. So gelingt es bekanntlich nicht, mit Leim selbst bei Ersatz fehlender Aminosäuren ${ }^{1}$ ) Stickstoffgleichgewicht herzustellen, und ebensowenig konnte der eine von uns mit Peter Rona ${ }^{2}$ ) einen Hund mit einem künstlichen Gemisch von Aminosäuren ins Stickstoffgleichgewicht bringen. Beim letzteren Versuche fehlten sicher manche Bausteine. Wir neigen vorläufig nach all unseren $\mathbf{E r}$ fahrungen der Ansicht zu, daß das Nahrungseiweiß, sofern seine Bausteine zur Synthese von Körpereiweiß Verwendung finden, nicht sofort zerstört wird, sondern, daß das assimidierte Eiweiß

1) Vgl. P. Rona und W. Müller, Über den Ersatz von Eiweiß durch Leim, Diese Zeitschrift, Bd. L, S. 263, 1907.

2) Emil Abderhalden und Peter Rona, Weitere Beiträge zur Kenntnis der Eiweißassimilation im tierischen Organismus, Diese Zeitschrift, Bd. XLVII, S. 397, 1906. 
zunächst als Baumaterial von Körperzellen usw. verwertet wird. ${ }^{3}$ ) Direkt abgebaut werden vielleicht diejenigen Bausteine, welehe bei der Umwandlung des Nahrungseiweißes in Körpereiweiß keine Verwendung finden, d. h: es ist die Möglichkeit vorhanden, daß nicht das gesamte Nahrungseiweiß mit all seinen Bausteinen am intermediären Zellstoffwechsel teilnimmt.

Eine unserer wichtigsten Aufgaben wird es sein, die eben kurz skizzierten Probleme einer Lösung näher zu bringen. Es wäre schon von allergrößtem Werte, wenn der Nachweis gelänge, daß unter bestimmten Umständen ein ganz spezifisch abgebautes Eiweiß zum Abbau kommt, d. h. wenn sich der Beweis erbringen ließe, daß schon assimiliertes Körpereiweiß verbrennt und nicht das eben aufgenommene, umgewandelte Nahrungseiweiß. Wir hofften, auf Grund der folgenden Beobachtung dieser Frage näher treten zu können. Bekanntlich gelingt es, beim Säugetier durch Einführung von Benzoesäure in gewissen Grenzen eine Ausscheidung von Hippursäure zu veranlassen. Diese bildet sich durch Kuppelung der eingegebenen Benzoesäure mit Glykokoll. Dieser Paarling stammt nach der allgemeinen Annahme zum weitaus größten Teil aus Eiweiß. In Betracht käme als Quelle noch die Harnsäure und vielleicht noch einige andere stickstoffhaltige Substanzen des tierischen Organismus, doch spielt die Menge des aus diesen Verbindungen und speziell der Harnsäure abzuleitenden Glykokolls gewiß keine bedeutende Rolle. Nun ist es von großem Interesse, daß die Pflanzenfresser nach Benzoesäurezufuhr viel mehr Hippursäure bilden als die Fleischfresser, d. h. bei diesen ist die Hippursäuresynthese beschränkter. Führt man z. B. einem Hunde reichlich Benzoesäure zu, so wird nur ein relativ kleiner Teil an Glykokoll gebunden ausgesehieden, der größte Teil erscheint als solche oder in einem noch unbekannten Umwandlungsprodukt im Harn. ${ }^{2}$ ) Leider ist bei allen derartigen

1) Vgl. hierzu Emil Abderhalden, Lehrbuch der physiologischen Chemie, 1906, S. $240 \mathrm{ff}$. und S. $678 \mathrm{ff}$.

2) Vgl. u. a. Theodor Brugsch und Rahel Hirsch, Hippursäuresynthese and Ausscheidung der Benzoesäure beim Funde, Zeitschrift fǜ experim. Pathol. u. Ther., Bd. HI, S. 663, 1906. 
Versuchen nie der Glykokollgehalt der zugeführten Nahrung berechnet und genauer bestimmt worden. Jedenfalls wird im allgemeinen ein sehr beträchtlicher Unterschied im Glykokollgehalt der Nahrung der Pflanzenfresser und speziell des wichtigsten Versuchstieres, des Kaninchens, und demjenigen der Nahrung des Fleischfressers kaum vorhanden sein. Es ist somit denkbar, daß das Kaninchen die Benzoesäurezufuhr mit dem Abbau besonders glykokollreicher Proteine seiner Gewebe beantwortet, d. h. es ist die Möglichkeit vorhanden, daß das Kaninchen Proteine in seinen Geweben enthält, die einen sehr großen Reichtum an Glykokoll aufweisen, während dies beim Fleischfresser vielleicht nicht der Fall ist. Ließe sich ein derartiger Unterschied feststellen, dann müßte es durch systematische Versuche gelingen, zu entscheiden, ob der tierische Organismus durch künstliche Mittel veranlaßt werden kann, bestimmte Proteine seiner Gewebe zum Abbau $\mathrm{zu}$ bringen. Damit ließe sich dann unter genauer Feststellung der Stickstoffbilanz wenigstens in engen Grenzen die Frage beantworten, ob das Nahrungseiweiß sofort vollständig verbrannt wird, oder ob nicht vielmehr Gewebseiweiß zerfällt und das neu assimilierte Eiweiß an dessen Stelle tritt. Es wäre ferner weiterhin von höchstem Interesse, die Wirkung einer Verarmung an einem bestimmten Protein $\mathrm{zu}$ verfolgen und festzustellen, in welcher Art der Wiederersatz erfolgt. Wir kämen dann auch zu ganz anderen Vorstellungen über die Eiweißeinschmelzung unter pathologischen Bedingungen. Es scheint uns überhaupt verfehlt, als Maßstab für die Störungen im Eiweißstoffwechsel einzig und allein die Höhe der Stickstoffausscheidung anzunehmen. Wir können uns sehr wohl vorstellen, daß einem wenig erhöhten Eiweißzerfall unter Umständen eine viel größere Bedeutung zukommt als einem ganz bedeutend erhöhten. Es wird gewiß auch auf die Art des zerfallenden Proteins ankommen. Nach unseren Vorstellungen über den Eiweißstoffwechsel baut sich jede Körperzelle aus dem Proteingemisch des Blut- resp. Lymphplasmas ihr eigenes Eiweiß auf. Je nach der Art des gebildeten Proteins werden bald mehr bald weniger, oft auch gar keine Bausteine ohne Verwendung bleiben, d. h. die Art 
des zu bildenden Proteins bestimmt den Eiweißverbrauch! Stellen wir uns vor, daß eine Zelle aus dem Plasmaeiweiß z. B. ein Histon bildet, dann muß gewiß ein beträchtlicher Umbau und ein bedeutender Wegfall an Monoaminosäuren stattfinden, um eine Anreicherung an Diaminosäuren herbeizuführen. Auf Grundlage dieser Vorstellung ist die Möglichkeit gegeben, daß eine relative kleine Einbuße an Zellprotein doch von weittragender Bedeutung für den Organismus werden kann, wenn sie Proteine betrifft, die in ihrer Zusammensetzung und ihrem Aufbau weit von Plasmaeiweiß abweichen. Vielleicht erklärt sich auf dieser Grundlage manche Kachexie ohne eine auffallend erhöhte Stickstoffausscheidung und anderseits braucht einer solchen kein entsprechend erhöhter Zelleiweißabbau zugrunde zu liegen. Im ersten Falle ist vielleicht ein Ersatz kleiner Mengen für das Zellleben sehr wichtiger Proteine unmöglich oder doch eingeschränkt und im letzteren Falle erfordert der Ersatz von zerfallenem Eiweiß Bausteine aus einer größeren Menge von Nahrungsproteinen, weil ein Eiweiß zu ersetzen ist, in dem eine bestimmte Gruppe von Aminosäuren in besonders großer Menge vorhanden ist. Die nicht verwendbaren, überschüssigen Aminosäuren würden die hohe Stickstoffausscheidung bedingen.

Als ersten Versuch nach dieser Richtung bestimmten wir im gesamten Organismus einiger Tierarten - Katze, Kaninchen und Huhn - den Gehalt an Glykokoll und zugleich auch an Glutaminsäure, um festzustellen, ob sich Unterschiede nachweisen lassen. Wir verarbeiteten in allen Fällen die gesamten Tiere. In Wegfall kamen nur das Fell, resp. das Gefieder und der Darminhalt. Der übrige Teil der Tiere wurde mit einer Fleischhackmaschine fein zerkleinert, und der Brei dann mit Alkohol so lange ausgekocht, bis er nichts mehr aufnahm. Nach weiterer Zerkleinerung wurde das Produkt so lange mit Äther im Soxhlet ausgezogen, bis eine Probe des abdestillierten Äthers keinen Rückstand mehr hinterließ. Wir trockneten nun einen aliquoten Teil der ganzen Masse bei $100^{\circ}$ bis zur Gewichtskonstanz, den übrigen Teil kochten wir 6 Stunden mit der 3 fachen Menge rauchender Salzsäure am Rückflußkühler. Die salzsaure Lösung wurde mit Wasser verdünnt, filtriert und 
auf ein bestimmtes Volumen gebracht. Einige Kubikzentimeter der gut gemischten Gesamtlösung verwendeten wir zur Bestimmung des Stickstoffgehaltes und einige zur Feststellung des Aschengehaltes. Die übrige Lösung wurde in genau zwei Hälften geteilt. Die eine diente zur Bestimmung der Glutaminsäure und die andere zur Glykokollbestimmung. Im ersteren Falle engten wir die dunkelbraune Lösung unter vermindertem Druck bis zur Trockene ein, lösten den Rückstand in ca. 1 l Wasser und schüttelten die Lösung zur Entfernung der Hauptmenge der noch vorhandenen Salzsäure mit einer gerade ausreichenden Menge von Kupferoxydul. Wir setzten davon soviel zu, bis die Lösung anfing sich blau zu färben. Nach erfolgter Filtration und sorgfältigem Auswaschen des Filterrückstandes mit Wasser entfernten wir das gelöste Kupfer mit Schwefelwasserstoff und engten dann die filtrierte, schwach gelb gefärbte Lösung unter vermindertem Druck stark ein. In der mit gasförmiger Salzsäure gesättigten Lösung erfolgte bald reichliche Krystallisation. Sie wurde auf Koliertuch abgenutscht und die Mutterlauge eingeengt. Dieser Prozeß wurde so lange wiederholt, als Glutaminsäurechlorhydrat sich noch ausschied. Das erhaltene Rohprodukt wurde über Kalk und Schwefelsäure annähernd getrocknet und noch zweimal aus verdünnter Salzsäure umkrystallisiert. Das schließlich erhaltene Produkt bildete große, wasserklare Krystalle.

Zur Bestimmung des Glykokolls wurde die zweite Hälfte der Gesamtlösung verwendet, und die salzsaure Lösung unter vermindertem Druck völlig zur Trockene verdampft. Der Rückstand wurde in gewohnter Weise durch Übergießen mit der fünffachen Menge absoluten Alkohols und Einleiten gasförmiger, trockener Salzsäure verestert. Die Veresterung wurde nach jedesmaligem Verdampfen der Lösung der salzsauren Ester bei einer $40^{\circ}$ nicht übersteigenden Temperatur des Wasserbades und etwa $12 \mathrm{~mm}$ Druck noch zweimal wiederholt. Schließlich wurde der Rückstand der salzsauren Ester in absolutem Äthylalkohol gelöst, die Lösung durch Filtration von den Salzen befreit und dann auf ein bestimmtes Volumen gebracht. In einem aliquoten Teil wurde der Gehalt an Salzsäure genau 
bestimmt. Wir setzten dann die Ester mit etwas weniger als der berechneten Menge Natriumalkoholat in Freiheit. Das ausgeschiedene Kochsalz wurde abzentrifugiert und die klare Lösung bei etwa $12 \mathrm{~mm}$ Druck bis $100^{\circ}$ des Wasserbades destilliert. Die Vorlage wurde mit einer Kältemischung sorgfältig gekühlt. Das Destillat, das den Alkohol und die übergegangenen Ester enthielt, wurde mit verdünnter Salzsäure geschüttelt und dann zur Trockene verdampft. Den gewogenen Rückstand übergossen wir mit der fünffachen Menge Alkohol und leiteten in diesen bis zur Sättigung gasförmige, trockene Salzsäure ein. Nach Einimpfen eines Kryställchens von Glykokollesterchlorhydrat und längerem Stehen auf Eis erfolgte reichliche Krystallabscheidung. Sie wurde abgenutscht, die Mutterlauge eingeengt und wieder auf Eis gestellt. Im ganzen erhielten wir 3-4 Krystallisationen. Sie wurden vereinigt und über Kalk und Schwefelsäure getrocknet.

Den Destillationsrückstand schüttelten wir mit Äther aus, um die Monoaminosäureester in Lösung zu bringen. Die stark gelb gefärbte Lösung dampften wir nach Zusatz von verdünnter Salzsäure ein. Der Rückstand wurde dann wie oben auf Glykokoll verarbeitet. Wir erhielten in keinem Falle eine $\mathrm{Ab}$ scheidung von Glykokollesterchlorhydrat.

Wir wollen gleich bemerken, daß die angeführte Methode der Glykokollbestimmung eine Fehlerquelle aufweist. Das verarbeitete Material war sehr salzreich und enthielt sicher auch chlorhaltige Verbindungen. Allerdings entfernten wir die Hauptmasse der Salze durch Alkohol. Geringe Mengen dürften jedoch dennoch in Lösung geblieben sein, und so ist die Bestimmung der Salzsäure durch Titration mit Silbernitrat und Rhodanammon unter Zusatz von Eisenalaun insofern nicht ganz einwandsfrei, als nicht ausschließlich die Hydrochlorate der Ester in Betracht kamen. Wir verwendeten stets etwas weniger als die berechnete Menge an Natriumalkoholat, um einen Überschuß zu vermeiden, denn ein solcher würde die Ausbeute an Aminosäureester bei der Destillation gewiß herabsetzen. Wir glauben nicht, daß diese Fehlerquelle, die wir sehr einschränkten, für die Beurteilung unserer Resultate von Bedeutung ist.

Im folgenden seien die Resultate angeführt: 
318 Emil Abderhalden, Alfred Gigon und Eduard Strauss,

\section{Katzen.}

Katze 1: ca. 6 Monate alt.

Trockensubstanz nach Behandlung mit Alkohol und Äther $355 \mathrm{~g}$.

Stickstoffgehalt des Hydrolysats: $38,86 \mathrm{~g}$, daraus Eiweiß berechnet: $242,87 \mathrm{~g}$.

Aschengehalt des Hydrolysats $64,7 \mathrm{~g}=\mathbf{1 8 , 2 3} \%$ der Trockensubstanz.

Trockensubstanz - Asche $=290,3 \mathrm{~g}$. Der Eiweißgehalt beträgt auf die aschefreie Substanz berechnet $\mathbf{8 3 , 6 6} \%$.

Glutaminsäurebestimmung: $30,25 \mathrm{~g}$ Glutaminsäure $=12,45 \%$ auf den berechneten Eiweißgehalt ausgerechnet. Glykokollbestimmung: Ausbeute an Glykokoll 8,1234 $\mathrm{g}$ $=\mathbf{3 , 3 4} \%$ auf Eiweiß berechnet.

Katze 2: ca. 1 Jahr alt.

Trockensubstanz nach Behandlung mit Alkohol und Äther $780 \mathrm{~g}$.

Stickstoffgehalt des Hydrolysats: $81,4 \mathrm{~g}$, daraus berechnet 508,75 g Eiweiß.

Aschengehalt des Hydrolysats 108,42 $\mathrm{g}=\mathbf{1 3 , 9} \%$ der Trockensubstanz.

Trockensubstanz - Asche: 671,6 g. Der Eiweißgehalt beträgt auf aschefreie Substanz berechnet $75,75 \%$.

Glutaminsäurebestimmung: $71,10 \mathrm{~g}$ Glutaminsäure $=13,97 \%$ auf den berechneten Eiweißgehalt ausgerechnet.

Glykokollbestimmung: $15,12 \mathrm{~g}$ Glykokoll $=\mathbf{2 , 9 7} \%$ auf Eiweiß berechnet.

Katze 3. Junges Tier, das zu einem anderen Versuchszwecke verhungert worden war. Wir verarbeiteten hier nur einen Teil der Trockensubstanz. Sie war sehr fein gepulvert und sehr gut gemischt worden.

Angewandte Trockensubstanz $75 \mathrm{~g}$. Stickstoffge halt des Hydrolysates 7,28 $\mathrm{g}=45,50 \mathrm{~g}$ Eiweiß.

Aschengehalt des Hydrolysates 16,2425 $\mathrm{g}=\mathbf{2 1 , 6 5} \%$ der Trockensubstanz.

Trockensubstanz - Asche: 58,76 g. Der Eiweißgehalt beträgt auf aschefreie Substanz berechnet 77,43\%. 
Über den Vorrat an einigen Aminosäuren bei verschiedenen Tierarten. 319

Glutaminsäurebestimmung: Erhalten: $5,81 \mathrm{~g}$ Glutaminsäure $=12,77 \%$ berechnet auf den Eiweißgehalt.

Glykokollbestimmung: Erhalten: 1,5012 g Glykokoll $=3,29 \%$ auf Eiweiß berechnet.

\section{Kaninchen.}

Kaninchen 1: ca. 1 Jahr alt.

Trockensubstanz nach Behandlung mit Alkohol und Äther $328 \mathrm{~g}$.

Stickstoffgehalt des Hydrolysates: $28,70 \mathrm{~g}=179,37 \mathrm{~g}$ Eiweiß.

Aschengehalt des Hydrolysates: 25,75 $\mathrm{g}=\mathbf{7 , 8 5} \%$ der Trockensubstanz.

Trockensubstanz - Asche $=302,25 \mathrm{~g}$, davon Eiweiß $\mathbf{5 9 , 3 4} \%$.

Glutaminsäurebestimmung: Gefunden $25,85 \mathrm{~g}$ Glutaminsäure $=\mathbf{1 4 , 4 1} \%$ des berechneten Eiweißes.

Glykokollbestimmung: Gefunden 4,1718 g Glykokoll $=\mathbf{2 , 3 3} \%$ des berechneten Eiweißes.

Dieser Wert ist wahrscheinlich etwas zu niedrig, weil die letzte Mutterlauge verloren ging.

Kaninchen 2: ca. 2 Jahre alt.

Trockensubstanz nach Behandlung mit Alkohol und Äther $601 \mathrm{~g}$.

Stickst offgehalt des Hydrolysates $55,25 \mathrm{~g}=345,31 \mathrm{~g}$ Eiweiß.

Aschengehalt des Hydrolysates: $54,15 \mathrm{~g}=\mathbf{8 , 0 8} \% \mathrm{oder}$ Trockensubstanz.

Trockensubstanz - Asche $=546,85 \mathrm{~g}$, davon Eiweiß $63,14 \%$.

Glutaminsäurebestimmung: Gefunden $48,25 \mathrm{~g}$ Glutaminsäure $=13,97 \%$ der berechneten Eiweißmenge.

Glykokollbestimmung: Gefunden 11,28 g Glykokoll $=\mathbf{3 , 2 7} \%$ der berechneten Eiweißmenge.

\section{Huhn.}

Trockensubstanz 235 g. Stickstoffgehalt des Hydrolysates $22,905 \mathrm{~g}=143,15 \mathrm{~g}$ Eiweiß. 
Aschengehalt des Hydrolysates 56,72 $\mathrm{g}=\mathbf{2 4 , 1 3} \%$ der Trockensubstanz.

Trockensubstanz - Asche: 178,28g, der Eiweißgehalt hiervon beträgt $80,29 \%$.

Glutaminsäurebestimmung: Gefunden 17,21 g Glutaminsäure $=12,02 \%$ des berechneten Eiweißgehaltes.

Glykokollbestimmung: Gefunden 4,5112 g Glykokoll $=\mathbf{3 , 1 5} \%$ des berechneten Eiweißgehaltes.

$\mathrm{Zu}$ den vorliegenden Bestimmungen ist $\mathrm{zu}$ bemerken, daß die Berechnung des Eiweißgehaltes natürlich eine nur annähernde ist, indem wir einfach den gefundenen Stickstoffgehalt mit 6,25 multiplizierten. Eine andere Berechnung der Ausbeuten an Glykokoll und an Glutaminsäure war ausgeschlossen. Die Beziehung zu dem berechneten Eiweißgehalt gibt noch das beste Bild. Eine Berechnung auf die aschefreie Trockensubstanz würde zu große Fehler in sich schließen. Wir glauben, daß unsere Art der Berechnung noch die am besten zu vergleichenden Werte ergab. In Wirklichkeit ist der berechnete Eiweißgehalt sicher zu hoch, und daher sind die Zahlen für Glykokoll und Glutaminsäure zu niedrig. Es liegt jedoch kein Grund für die Annahme vor, daß bei den einzelnen Tieren sehr große Unterschiede zwischen dem wirklichen Eiweißgehalt und den übrigen stickstoffhaltigen Substanzen vorhanden waren.

Was die Bestimmung des Glykokolls anbetrifft, so ist zu bemerken, daß seine Abscheidung als Esterchlorhydrat keine quantitative ist. Immerhin dürfte bei der in allen Fällen ganz gleichartigen Methodik die nicht bestimmte Glykokollmenge eine im ganzen gleichartige gewesen sein, so daß die gefundenen Zahlen gut vergleichbar sind. Die Werte für die Glutaminsäure sind aus dem isolierten salzsauren Salz berechnet. Dieses selbst kam erst zur letzten Wägung, nachdem es durch mehrfaches Umkrystallisieren völlig gereinigt worden war. Die ersten Krystallisationen waren stets recht unrein und hatten dementsprechend ein größeres Gewicht. In der folgenden Übersicht geben wir die gefundenen Ausbeuten an Glykokoll und Glutaminsäure wieder. Die Zahlen beziehen sich auf $100 \mathrm{~g}$ Eiweiß. 


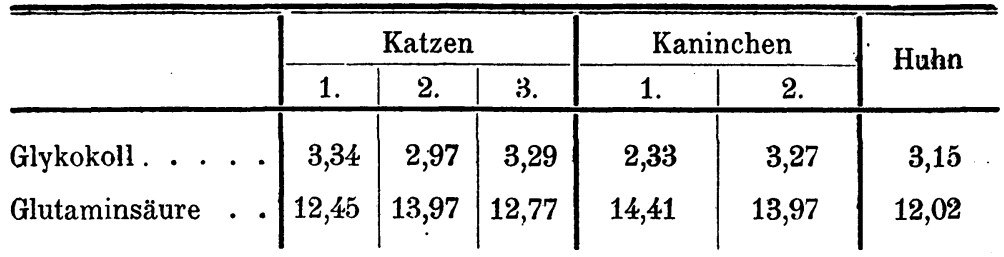

Diese Übersicht zeigt, daß die untersuchten Tiere, trotzdem sie alle eine ganz verschiedenartige Nahrung aufgenommen hatten, einen fast übereinstimmenden Gehalt an Glykokoll and Glutaminsäure aufweisen. Unsere Vermutung, daß das Kaninchen als Vertreter der Pflanzenfresser einen höheren Gehalt an Glykokoll aufweisen würde, hat sich somit nicht bestätigt. Es darf jedoch nicht übersehen werden, daß unsere Bestimmung eine sehr rohe und außerdem die Zahl der untersuchten Tiere eine noch kleine ist. Unsere Untersuchung gibt nur einen Durchschnittswert, sie sagt nichts aus über die Art der Bindung des Glykokolls. Es ist nicht ausgeschlossen, daß das Kaninchen seinen Vorrat an Glykokoll zum Teil wenigstens in Bindungen besitzt, aus denen es leicht abspaltbar ist, während die Katze in geringerem Maße über solche Verbindungen verfügt. Über solche Unterschiede sagt unsere Untersuchung natürlich nichts aus. Hier müßten systematische Untersuchungen über den Glykokollgehalt der verschiedenen Organe einsetzen. Würde es gelingen, große Unterschiede im Glykokollgehalt bestimmter Organe bei verschiedenen Tieren aufzufinden, dann wäre es lohnend, zu untersuchen, ob nach Benzoesäurefütterung eine Abnahme des Glykokollgehaltes eintritt, und in welchem Umfange der gesamte Eiweißstoffwechsel beeinflußt wird.

Unser Versuch zeigt auf alle Fälle, mit welch großer Schwierigkeit jede Fragestelluug im Gebiete des Eiweißstoffwechsels zu kämpfen hat. Jede präzise Fragestellung kompliziert sich zu zahllosen Einzelfragen, sobald man eine Antwort sucht. Dieser Umstand beweist, wie gering auch jetzt noch unsere tatsächlichen Kenntnisse des intermediären Eiweißstoffwechsels sind. Wir wollen nicht unerwähnt lassen, daß unsere Untersuchung vielleicht eine Stütze für die Annahme abgibt, daß das Glykokoll, das bei Zufuhr von Benzoesäure aus dem 
322 Abderhalden, Gigon und Strauss, Über Aminosäuren.

Körper ausgeführt wird, wenigstens zum Teil synthetisch gebildet wird. Daß etwa, wie Wiechowski1) annimmt, der normale Abbau des Eiweißes über das Glykokoll erfolgt, scheint uns höchst unwahrscheinlich, vielmehr sind wir der Ansicht, daß die Art des Eiweißabbaus in den Geweben keinen starren Gesetzen folgt, sondern den bestehenden Verhältnissen angepaßt wird. $\mathrm{Ob}$ jedoch aus anderen Aminosäuren direkt Glykokoll durch Abbau entsteht, scheint uns sehr fraglich, ebenso findet die Annahme einstweilen keine Stütze, daß die Hydrolyse der Proteine durch die Gewebsfermente zu anderen Produkten führt, als die Hydrolyse in vitro. Wenn es sich tatsächlich bestätigen sollte, daß weitaus größere Mengen von Hippursäure auf Benzoesäurezufuhr entstehen, als dem zur Verfügung stehenden Glykokoll entspricht, dann ist die Annahme einstweilen plausibler, daß diese Aminosäure synthetisch gebildet wird, und zwar schon deshalb, weil der Organismus möglicherweise auf diese Synthese schon vorbereitet ist. Die beständige Ausfuhr der Gallensäuren mit der Galle, die alle Glykokoll als Paarling enthalten, darf nicht unbeachtet bleiben, ebenso die Tatsache, daß als einzige Aminosäure im normalen Urin bis jetzt Glykokoll mit Sicherheit nachgewiesen worden ist. Die Leichtigkeit, mit welcher der Säugetierorganismus anscheinend Glykokoll bildet, ist möglicherweise eine phylogenetisch nicht unwichtige Erscheinung und vielleicht ein Anklang an die Synthese der Harnsäure bei den Vögeln und Reptilien. Es spricht ja manches dafür, daß bei diesen Tierklassen das Glykokoll eine Rolle bei der Harnsäurebildung spielt. Es ist jedenfalls von höchstem Interesse, die Bildung dieser Aminosäuren noch genauer zu verfolgen.

1) Wilhelm Wiechowski, Die Gesetze der Hippursäuresynthese. (Zugleich ein Beitrag zur Frage der Stellung des Glykokolls im Stoffwechsel.) Hofmeisters Beiträge, Bd. VII, S. 204, 1905. 